\title{
O DIREITO À LIBERDADE A PARTIR DO DESENVOLVIMENTO NO ÂMBITO DAS CIDADES
}

\author{
Eduardo Felipe Veronese ${ }^{1}$
}

\section{RESUMO:}

O presente trabalho apresenta uma abordagem acerca dos direitos fundamentais previstos na Constituição Federal e como eles podem ser postos à disposição dos indivíduos. Isso, pois, realizar-se-á uma análise do direito ao desenvolvimento econômico e social no âmbito da cidade, ente federativo mais próximo às demandas sociais e, por conseguinte, com maior disponibilidade para a implementação de políticas públicas capazes de satisfazer, mesmo que minimamente, as necessidades dos indivíduos, para que participem da sociedade, como verdadeiros atores sociais, possibilitando que os direitos, especialmente os sociais, sejam assegurados, proporcionando a liberdade aos integrantes da sociedade.

Palavras-chave: Desenvolvimento da cidade; direitos fundamentais; direito à cidade; políticas públicas; desenvolvimento como liberdade.

\section{THE RIGHT TO FREEDOM FROM DEVELOPMENT WITHIN THE CITIES}

\begin{abstract}
:
The present work presents an approach about the fundamental rights foreseen in the Federal Constitution and how they can be made available to individuals. This, therefore, will carry out an analysis of the right to economic and social development within the city, a federative entity closest to social demands and, therefore, with greater availability for the implementation of public policies capable of satisfying, even if minimally, the needs of individuals, to participate in society, as true social actors, enabling rights, especially social ones, to be guaranteed, providing freedom to members of society.
\end{abstract}

Keywords: Development of the city; fundamental rights; right to the city; public policy; development as freedom.

\section{INTRODUÇÃO}

O Estado Liberal, conforme concebido, se apresenta ultrapassado, não possuindo mais condições de perpetuar seus fundamentos, sem que haja a devida mitigação, na sociedade atual. Assim, existe a demanda social por direitos de liberdade, no sentido de não intervenção do Estado nas garantias individuais dos integrantes da sociedade, a fim de conferir a devida igualdade entre todos, ao mesmo tempo em que se demanda a participação

\footnotetext{
${ }^{1}$ Mestre em Direito Empresarial e Cidadania na Faculdade de Direito do Centro Universitário Curitiba Unicuritiba. Especialista em Direito e Processo Civil na Faculdade de Direito do Centro Universitário Curitiba Unicuritiba. Especialista em Direito Administrativo pelo Instituto de Direito Romeu Felipe Bacellar. Bacharel em Direito pela Universidade Positivo - UP. eduardo@borgeseveronese.adv.br
} 
ativa do Estado, por meio da implementação de prestações positivas capazes de, se não encerrar, ao menos reduzir os efeitos das desigualdades sociais.

Com isso, o Estado assume uma roupagem intervencionista, ao menos parcialmente, dentro de um contexto em que prevalece a busca contínua pelo capital e pelo aumento de riquezas. O Estado é demandado a atuar para favorecer aqueles que possuem poucas ou não possuem condições de garantir a sua dignidade enquanto pessoa humana.

Os indivíduos inseridos no contexto social apenas serão de fato livres quando a eles for garantido o acesso aos mecanismos que lhes possibilitem viver da forma como melhor lhes satisfaça, sem obrigação de submissão a situações para a garantia da subsistência.

Para tanto, dentre os entes federativos, conforme previsto na Constituição Federal, o município é o detentor de maior capacidade para acompanhar as demandas sociais e implementar ações com vias à satisfação dos interesses da coletividade, razão pela qual o presente trabalho possui como ponto de partida da análise o contexto da cidade e a sua relevância face aos indivíduos que nela estão inseridos.

Faz-se necessário, então, no âmbito da cidade promover o desenvolvimento econômico e social, direcionado à promoção dos direitos fundamentais individuais e coletivos, a partir dos mecanismos que a ela são disponibilizados.

Para salvaguardar os direitos, a cidade precisa implementar políticas públicas, a partir de escolhas alocativas, para a satisfação dos interesses da sociedade. Entretanto, as ações afirmativas pelo Poder Público demandam recursos, que infelizmente são escassos, razão pela qual não se faz possível atender tudo e todos.

Nesse aspecto emerge o objetivo geral de identificar os meios de assegurar o acesso a direitos fundamentais, não apenas de liberdade, mas também de igualdade e fraternidade, pelos indivíduos no contexto da cidade, adotando o método dedutivo acerca do tema, analisando as questões de desenvolvimento social e econômico da cidade.

\section{DIREITO AO DESENVOLVIMENTO E CIDADANIA}

A cidade pode ser entendida como uma obra resultado da relação dialética e imaterial entre os diversos atores sociais, compreendidos indivíduos e grupos, de natureza mutuamente interferente em áreas diversas, em contato com a cultura e as leis. (LEFEVBRE, 2005, p. 46)

A urbanização das cidades é decorrência direta do processo de industrialização, que conferiu novas configurações às cidades e sua relação com o campo, bem como resultou em 
grande parte dos problemas nelas vivenciados, como o crescimento desordenado e o modo de vida das pessoas, proveniente das ações humanas com caráter simbiótico, pois os benefícios aos interessados são proporcionados de maneira desproporcional. (LEFEVBRE, 2005, p. 48)

O processo de industrialização foi decorrente do início do período de ascensão do capitalismo, sob forte influência dos ideais difundidos no modelo econômico liberal, regendo, portanto, a vida econômica nas cidades.

A consequência da implementação desse modelo econômico foi o início da crise nas cidades, não obstante a ocorrência da explosão e proliferação dos centros urbanos, permeados pelas ações especificamente direcionadas à manutenção do poder econômico.

\footnotetext{
Sim, esta cidade que atravessa tantas vicissitudes e metamorfoses, desde seus núcleos arcaicos que seguiram de perto a aldeia, essa forma social admirável, essa obra por excelência da práxis e da civilização se desfaz e se refaz sob nossos olhos. [...] Quando emergiram os problemas de conjunto, sob o nome de urbanismo, foram eles subordinados à organização geral da indústria. Atacada ao mesmo tempo por cima e por baixo, a cidade se alinha pela empresa industrial; figura na planificação como engrenagem; torna-se dispositivo material próprio para se organizar a produção, para controlar a vida quotidiana dos produtores e o consumo dos produtos. Rebaixada para o nível de meio, ela estende a programação para o lado dos consumidores e do consumo; serve para regulamentar, para ajustar uma sobre a outra, a produção das mercadorias e a destruição dos produtos através da atividade devoradora chamada “consumo”. (LEFEVBRE, 2005, p. 76).
}

Desde o início do processo de industrialização, as cidades estavam diretamente atreladas às empresas, organizando-se a partir dos interesses dos produtores de riquezas, que não necessariamente coincidiam com os objetivos e necessidades dos demais integrantes da sociedade.

Nesse cenário é que surge o Direito à Cidade, como pressuposto jurídico-teórico do desenvolvimento econômico harmônico, ao qual se vincula a necessária compreensão da interface desse ramo normativo com o desenvolvimento a partir das necessidades dos atores sociais.

O Direito à Cidade, portanto, está ligado às necessidades sociais. Entretanto, não se está a abordar as necessidades individualmente tomadas como potencialidade de consumo isolado e seletivo de produtos e bens. O que se pretende é abarcar a perspectiva que 
transcende essa individualidade e assume proporções coletivas e difusas. Trata-se, então, de um sentimento de solidariedade, inserido na sociedade, em que há uma preocupação com o bem-estar geral, no presente e no futuro. (LEFEVBRE, 2005, p. 79)

Considerando os postulados do Estado Social de Direito, pela necessidade de realização dos valores de liberdade, igualdade e dignidade da pessoa, consagrados na Constituição Federal, não se pode mais pensar na cidade meramente como defesa de interesses particulares para a satisfação individual que não corresponda, ao mesmo tempo, no atendimento aos anseios da coletividade.

A cidade representa um lugar de realização de vida aos seus integrantes, razão pela qual o Direito à Cidade precisa ser analisado a partir do espaço urbano e de suas implicações socioeconômicas, políticas e culturais, objetivando a concretização da distribuição, ao menos de forma aproximada, equitativa e qualitativamente, dos recursos necessários à fruição dos direitos sociais. (PIOVESAN, 2004, p. 22)

A superação da crise nas cidades se dá por meio da construção de nova urbanidade, ditada pelos critérios de necessidades atuais, desconsiderando, para tanto, os ideais meramente capitalistas de reinvestimento dos lucros, mas objetivando a satisfação do direito fundamental e humano ao desenvolvimento, que engloba toda a gama de direitos sociais, assumindo caráter de prestação positiva pelo Estado na defesa da participação dos indivíduos no contexto da sociedade. (LEFEVBRE, 2005, p. 88)

O direito ao desenvolvimento, atualmente, é consagrado como um direito fundamental. Isso, pois, após longos debates por todo o mundo, durante vários anos, chegouse ao marco conceitual dessa evolução social, qual seja, inicialmente, a Carta Africana de Direitos de Humanos e dos Povos, de 1981. Em seguida, a Declaração sobre o Direito ao Desenvolvimento, aprovada pela Assembleia Geral das Nações Unidas, em 1986, foi responsável por reafirmar e conferir ainda maior amplitude ao conceito.

Por consequência, a análise do tema passou a ocorrer principalmente a partir do disposto no artigo $2^{\circ}$ da referida Declaração, que estabelece que "a pessoa humana é o sujeito central do desenvolvimento e deve ser o participante ativo e o beneficiário do direito ao desenvolvimento".

Entretanto, o reconhecimento definitivo do direito ao desenvolvimento sendo integrante do rol de direitos humanos foi consagrado definitivamente na Conferência de Viena de 1993 sobre Direitos Humanos no capítulo I, ponto10, dispondo que "a Conferência 
Mundial sobre Direitos do Homem reafirma o direito ao desenvolvimento, conforme estabelecido na Declaração sobre o Direito ao Desenvolvimento, enquanto direito universal e inalienável e parte integrante dos Direitos do homem fundamentais".

Nesse sentido, tem-se que o direito ao desenvolvimento é reconhecido pela Organização das Nações Unidas (ONU) como um direito humano fundamental e indisponível, não diferenciando a sua carga valorativa dos demais direitos fundamentais, reconhecendo-o, ainda, como um direito a igualdade de oportunidades aos indivíduos, entendidos como os atores sociais, aqueles por quem e para quem existe a sociedade. (FERREIRA; CASTRO. 2004, p. 31)

O direito ao desenvolvimento passou a ser, então, juntamente com diversos outros, um direito fundamental de todo indivíduo, atribuindo, por consequência, ao Estado a responsabilidade de promovê-lo e efetivá-lo. Sendo assim, a concretização do direito ao desenvolvimento envolve um enorme arcabouço de elementos, sendo difícil pensar que o desenvolvimento possa realmente ser visto independentemente de seus componentes econômicos, sociais, políticos ou jurídicos, devendo haver a participação ativa da sociedade para que haja o efetivo desenvolvimento. (SEN, 2005, p. 3)

Ressalte-se que o desenvolvimento econômico não é sinônimo de crescimento econômico, devendo tais conceitos serem tomados de forma distinta e contextualizada.

No que tange ao crescimento econômico, tem-se o acúmulo de riquezas, que não se vincula às causas sociais, liberdade política, garantia dos direitos civis e liberdades substantivas. (SEN, 2010, p. 47)

Trata-se de aumento dos indicadores de produtividade, de bens e serviços, vinculados a determinado espaço geográfico. Refere-se, portanto, ao crescimento quantitativo do produto agregado, indicando pelo produto interno bruto o nível de variação.

Por outro lado, o desenvolvimento econômico demanda uma análise mais ampla, vinculando-se às mudanças mais profundas na economia e na sociedade, sendo o crescimento econômico um dos fatores que interferem no cálculo do desenvolvimento.

(...) o desenvolvimento tem a ver, primeiro e acima de tudo, com a possibilidade de as pessoas viverem o tipo de vida que escolheram, e com a provisão dos instrumentos e das oportunidades para fazerem as suas escolhas. [...] essa é uma idéia tão política quanto econômica. Vai desde a proteção dos direitos humanos até o aprofundamento da democracia (VEIGA, 2010, p. 81). 
Tem-se, então, que o desenvolvimento econômico não indica apenas um aumento de riqueza pontual, mas uma melhoria do bem-estar social, em consequência da implementação de ações afirmativas para a promoção da máxima igualdade possível no acesso aos diversos fatores sociais.

Esse direito, ligado à gama de direitos constitucionais fundamentais e humanos previstos expressamente ou implicitamente na Constituição Federal, é definido pela jurisprudência e pela doutrina constitucional como direito de terceira dimensão, transcendendo a individualidade do ser humano e visando atender aos anseios das presentes e futuras gerações, importando em preocupações para além do espectro individual egoístico. (SARLET, 2006, p. 293)

Cumpre, entretanto, destacar os conceitos de direito ao desenvolvimento e direito do desenvolvimento, que, apesar de costumeiramente estarem atrelados, pois possuem origem comum no desenvolvimento, são detentores de cargas valorativas diferentes.

\footnotetext{
Nesse itinerário estaria, em apertada síntese, o percurso entre o direito do desenvolvimento e o direito ao desenvolvimento. A mudança se tornou mais evidente quando os aspectos econômicos do desenvolvimento começaram a perder fôlego, impulsionados pelo agudizamento dos conflitos nas relações Norte-Sul e nas relações dos países em desenvolvimento entre si e pelo avanço do processo de globalização dos mercados, tendo ganhado projeção, em contrapartida, os aspectos plurais e transversais da abordagem de desenvolvimento, que passou a perceber as demandas humanas, superando o contexto macroeconômico; assim, entram em cena temas como o respeito às minorias, a autodeterminação dos povos e sua identidade social e cultural, para além da questão da circunscrição nacional ou regional de políticas econômicas permeáveis à proteção internacional. (FEITOSA, 2013, p. 173).
}

O direito do desenvolvimento está intimamente vinculado ao contexto do direito econômico constitucional, sendo direcionado especialmente às interações existentes entre o estado e os agentes de mercado, com vistas ao atendimento dos interesses sociais, por meio de estratégias econômicas que integrem os fenômenos socioeconômicos de prestação positiva pelo Estado, principalmente os direitos sociais e a ordem econômica, previstos no artigo $6^{\circ}$ e 
170 da Constituição Federal, respectivamente, visto que podem ser especificamente positivados. (SARLET, 2006, p. 295)

Por outro lado, o direito ao desenvolvimento se mostra mais abrangente que o direito do desenvolvimento, estando inserido entre os direitos humanos indisponíveis, sendo direito de solidariedade na dimensão da coletividade. Assim, serve o direito ao desenvolvimento para a proteção, não apenas promoção, da dignidade da pessoa humana, voltado à satisfação de indivíduos, coletividades e povos. (FEITOSA, 2013, p. 180)

Nesse aspecto, constata-se que o direito do desenvolvimento possui menor amplitude e alcance que o direito ao desenvolvimento, sendo o primeiro um instrumento à concretização do segundo. Conforme disposto nos artigos $2^{\circ}, 4^{\circ}$ e $6^{\circ}$ da Declaração sobre o Direito ao Desenvolvimento, compete aos Estados a formulação e implementação de políticas para a efetivação dos direitos econômicos e sociais dos indivíduos, com vistas à satisfação do direito ao desenvolvimento, que é um bem jurídico plural.

Desde o preâmbulo da Constituição Federal, mesmo que não tenha força normativa, já existe o compromisso de ações visando assegurar o desenvolvimento da sociedade brasileira. O desenvolvimento nacional, consagrado no artigo $3^{\circ}$, inciso II, da Constituição Federal, como um dos objetivos fundamentais da República Federativa do Brasil, tem por anseio a evolução, a partir de um conjunto elaborado de políticas econômicas voltadas aos interesses coletivos, do bem-estar de todos os indivíduos inseridos na sociedade, nos diversos campos de abrangência, como economia, cultura e política.

A Constituição da República Federativa do Brasil, de 1988, trata-se de uma Carta programática, de modo que os princípios previstos como objetivos fundamentais devem servir como parâmetro de interpretação e aplicação das demais normas inseridas no ordenamento jurídico pátrio, assim como impõem diretrizes cogentes às ações públicas.

Os fins e os meios do desenvolvimento requerem análise e exame minuciosos para uma compreensão mais plena do processo de desenvolvimento; é sem dúvida inadequado adotar como nosso objetivo básico apenas a maximização da renda ou da riqueza, que é, como observou Aristóteles "meramente útil e em proveito de alguma outra coisa". Sendo assim, o desenvolvimento deve estar relacionado sobretudo com a melhora da vida que levamos e das liberdades que desfrutamos. (SEN, 2010, p. 46) 
Nesse aspecto, o desenvolvimento está intimamente vinculado à satisfação dos direitos fundamentais dos indivíduos inseridos na sociedade, não apenas o aumento de renda ou riqueza. A liberdade individual não se limita à garantia formal de tratamento igualitário perante a lei, mas demanda, também, a concretização, material, da melhora das condições de vida.

A democracia, como corolário das sociedades contemporâneas de pensamento ocidental, trata-se de regime que por sua natureza deve beneficiar todos os integrantes de uma sociedade, tendo em vista que seu objetivo é permitir que todos sejam cidadãos de verdade, usufruindo de todos os direitos a eles atribuídos. No contexto da sociedade moderna, é inimaginável a existência de cidadania sem que haja, para tanto, a disponibilidade para usufruir plenamente dos direitos formalmente assegurados aos indivíduos.

Ou seja, a garantia do desenvolvimento passa, incontestavelmente, pela ampliação das liberdades dos indivíduos, sendo essas liberdades o principal fim e o principal meio do desenvolvimento, consagrando, por consequência, o constitucionalismo democrático. (SEN, 2010, p. 57)

Para Amartya Sen, a liberdade possui sentido amplo, englobando tanto a liberdade negativa, aquela decorrente da ausência de obstáculos que impedem o exercício de direitos, quanto a liberdade positiva, correspondente à existência de meios ou instrumentos para que as pessoas exerçam as suas capacidades da forma como melhor lhes convir. Portanto, a liberdade está relacionada com a possibilidade do indivíduo fazer escolhas e possuir mecanismos hábeis para concretiza-las. (MACHADO SEGUNDO, 2013, p. 39)

O valor dessa liberdade decorre de duas razões principais, quais sejam, conferir mais oportunidade para as pessoas buscarem seus objetivos e a importância do processo de escolha atribuído ao indivíduo. Havendo a liberdade, confere-se validade às escolhas, que não estarão sendo realizadas mediante coação, em razão de limitações impostas por terceiros. (SEN, 2010, p. 26)

Além do crescimento econômico, da evolução dos índices de riquezas materiais, as liberdades substantivas são elementos indispensáveis à concretização do verdadeiro e pleno desenvolvimento, sendo de extrema relevância a possibilidade dos indivíduos viverem, nessa sociedade, da forma que gostariam: 
A utilidade da riqueza está nas coisas que ela pode nos permitir fazer - as liberdades substantivas que ela nos ajuda a obter. Mas essa relação não é exclusiva (porque existem outras influências significativas em nossa vida, além da riqueza) nem uniforme (pois o impacto da riqueza em nossa vida varia conforme outras influências). (...) Uma concepção adequada de desenvolvimento deve ir muito além da acumulação de riqueza e do crescimento do Produto Nacional Bruto e de outras variáveis relacionadas à renda. (SEN, 2010, p. 28)

Portanto, para Amartya Sen, o indivíduo é o sujeito principal no processo de desenvolvimento, superando a análise sob a ótica preponderante do crescimento econômico, ou seja, do direito do desenvolvimento. Para o referido autor, o indivíduo é capacitado a interagir, a partir dos seus anseios e conforme a sua satisfação, para influenciar o contexto social em que está inserido.

Na democracia, o povo é o detentor do poder para a escolha daquele indivíduo a quem será atribuído o direito/dever de representar e concretizar os anseios da coletividade, assim como esse mesmo povo é detentor da prerrogativa de modificação da coordenação do Estado quando os objetivos não estiverem sendo cumpridos, o que confere a cada indivíduo o papel central nas decisões e na conformação da soberania popular, pelo exercício da cidadania.

Para a ocorrência do desenvolvimento, o crescimento econômico precisa estar atrelado à garantia de liberdade dos indivíduos. $\mathrm{O}$ aumento dos índices de renda e riquezas, acompanhados de privações de liberdades individuais não corresponde a desenvolvimento.

Sobre o tema, Bercovicci (2013, p. 53) esclarece que "quando não ocorre nenhuma transformação, seja social, seja no sistema produtivo, não se está diante de um processo de desenvolvimento, mas de modernização, mantendo o subdesenvolvimento, agravando a concentração de renda”.

O desenvolvimento não pode ser analisado exclusivamente baseado no crescimento econômico, nos índices do produto interno bruto, deve ter sua existência voltada ao cuidado dos setores sociais, sendo "importante ver o desenvolvimento como um processo de expansão das liberdades reais que as pessoas desfrutam, e essa expansão é considerada um fim primordial e o principal meio do desenvolvimento". (SEN, 2015, p. 55)

Amartya Sen, em sua obra intitulada "Desenvolvimento como liberdade", elenca cinco liberdades instrumentais como meio para alcançar o pleno desenvolvimento, quais 
sejam: i) as liberdades políticas, que correspondem aos direitos individuais de exercício da cidadania, de participação nas decisões sobre os rumos a serem tomados pelo Estado; ii) as facilidades econômicas decorrentes de rendas auferidas, como consequência do crescimento econômico, mas voltada à distribuição da renda de modo a possibilitar que todos os indivíduos tenham poder de consumo, possibilidade de produção e troca de produtos, aumentando a riqueza; iii) o acesso às oportunidades sociais, que diz respeito às formas do indivíduo viver melhor, por meio de políticas de saúde pública, educação de qualidade, saneamento básico, combate à fome, entre outros; iv) a garantia de transparência, visto como forma de combate à corrupção; e v) a segurança social. (SEN, 2010, p. 60)

A partir da referida doutrina, para a ocorrência do desenvolvimento no contexto da cidade, deve a Administração Pública despender esforços não apenas em prol da produção e acúmulo de riquezas, elevando os índices econômicos, mas principalmente efetivando a liberdade dos indivíduos nas escolhas que lhes são possíveis, valorizando as capacidades e garantindo direitos.

Assim, o crescimento econômico se configura em desenvolvimento econômico quando corresponde ao aprimoramento da qualidade de vida dos indivíduos inseridos na sociedade, tratando-se não da riqueza em quantidade, mas em qualidade. O desenvolvimento da cidade deve garantir aos indivíduos o exercício dos direitos de cidadania, da participação ativa como ator social.

O crescimento ou o desenvolvimento não pode ser mensurado sem que, para tanto, seja considerado o que realmente acontece na vida das pessoas que estão inseridas no contexto. O desenvolvimento está restrito à concepção de que as pessoas são agentes centrais da sociedade, devendo a elas estarem direcionadas as ações para a garantia das liberdades.

Por esses conceitos, o desenvolvimento econômico de um país deve, obrigatoriamente, também significar desenvolvimento do bem-estar social. A concepção de desigualdade reside nas diferenças de oportunidades pela privação de liberdades básicas, na desigualdade em relação ao indivíduo isolado, na omissão em relação às garantias de condições básicas de existência aos indivíduos, como acesso à saúde, educação, saneamento básico e alimentos, únicos elementos capazes de serem proximamente igualados entre os indivíduos empiricamente tão diversos. Para que ocorra o desenvolvimento as pessoas devem ser cidadãs. Porém, com a ocorrência de privação de direitos básicos, elas jamais entenderão a 
importância que têm para a sociedade em que vivem, enquanto o desenvolvimento, de fato, não ocorre. (SEN, 2010, p. 72)

\section{A CIDADE COMO AMBIENTE DE ACESSO A DIREITOS}

O Direito à Cidade corresponde a um direito que envolve, de forma cumulativa e não geracional, a proteção de direitos individuais civis e políticos e de direitos sociais em sua amplitude (econômicos, culturais e ambientais), evidenciando seu caráter de direito material, estando incluído no rol dos direitos fundamentais e humanos, e, no aspecto social, ligado diretamente ao Direito Humano ao Desenvolvimento, que se realiza pela efetividade dos direitos sociais, econômicos e culturais. (SARLET, 2006, p. 294)

Atribui-se, então, à cidade um dever de prestação positiva em favor dos indivíduos que a integram, como forma de retribuição à outorga de poderes quando da organização do Estado, satisfazendo integralmente a finalidade dessa entidade despersonalizada.

O direito à cidade é muito mais que a liberdade individual para acessar os recursos urbanos: é o direito de mudar a si mesmos por mudar a cidade. É, sobretudo, um direito comum, ao invés de individual, pois esta transformação inevitavelmente depende do exercício de um poder coletivo para dar nova forma ao processo de urbanização. $\mathrm{O}$ direito a fazer e refazer as cidades é também o direito de refazer a nós mesmos e assim um dos mais preciosos, e ainda assim mais negligenciados, de nossos direitos humanos. (HARVEY, 2012, p. 74).

A previsão do artigo 174 da Constituição Federal evidencia a opção realizada pelo legislador quando da elaboração da Carta Magna, encerrando definitivamente a concepção de Estado ausente para a implementação de um Estado absolutamente presente no setor econômico.

Seguindo esse raciocínio, compete ao Estado implementar ações positivas capazes de assegurar o cumprimento dos objetivos fundamentais da República Federativa do Brasil, dispostos no seu artigo $3^{\circ}$, todos eles tendentes a garantir as liberdades individuais, especialmente no sentido de conferir a igualdade material, não apenas formal.

O direito ao desenvolvimento se perfaz em direito fundamental dos indivíduos, vinculando, por consequência, a atuação do Estado na promoção da qualidade de vida à população, compatibilizando a ordem econômica e a ordem social. 
Para tanto, o grau de desenvolvimento passa a ser auferido especialmente pelas condições materiais que são dispostas a uma população para o seu bem-estar, não dependendo exclusivamente da medida de renda per capita para a garantia de melhor nível de vida. (DERANI, 2001, p. 32)

Esse desenvolvimento passa, sem dúvida, pela participação ativa dos integrantes da sociedade, mas depende, principalmente, da implementação de políticas afirmativas por parte do Poder Público, que é o detentor de prerrogativas e sujeições no contexto do Estado atualmente existente, principalmente em decorrência da implementação dos conceitos de social democracia.

Nesse aspecto, a Constituição federal prevê, em seu artigo 23, o rol de competências comuns da União, Estado, Distrito Federal e Municípios para atuação em favor dos interesses coletivos, numa análise de ações mais abrangentes na sociedade.

Tratando-se de um Estado organizado a partir de diversos entes, a satisfação das necessidades da população deve se dar especialmente a partir de políticas públicas realizadas por aqueles que estão mais próximos e detém maior contato com os indivíduos. Ou seja, as ações com vistas a garantir o pleno desenvolvimento são obrigações de todos os entes, mas devem tomar maior atenção no contexto das cidades, por serem elas as mais próximas às necessidades da população.

O operador do direito precisa olhar o município sob a ótica da Constituição Federal de 1988, ou seja, uma pessoa jurídica autônoma, pujante, com diversas competências, enfim, com uma gama bastante grande de atribuições para servir à população. $O$ fortalecimento do município representa, por consequência, o fortalecimento da democracia no país. Um município atuante significa menos problemas para o Estado e, por extensão, para a União. (BONAVIDES, 2004, p. 314)

Ressalte-se que os municípios receberam grande importância a partir da Constituição Federal de 1988, tratando-se de unidades federativas com autonomia, competência e discriminação de rendas.

O princípio federativo brasileiro se traduz pela autonomia recíproca constitucionalmente assegurada da União, dos Estados Federados e dos Municípios. 
O Município é peça estrutural do regime federativo brasileiro, à semelhança da União e dos próprios Estados.

A Constituição Federal estabelece uma verdadeira paridade de tratamento entre o Município e as demais pessoas jurídicas, assegurando-lhe autonomia de autogoverno, de administração própria e de legislação própria no âmbito de sua competência (art. 29, I, e 30 e incisos). (BASTOS, 2001, p. 319)

Tanto é que, para assegurar a participação direta e ativa dos municípios nas ações em favor dos interesses da coletividade, a Constituição Federal fixou, em seu artigo 30, o rol de competências atribuídas diretamente aos municípios, sendo que, dentre elas, está a competência para legislar sobre assuntos de interesse local.

É verdade que o conceito de interesse local tem certa imprecisão, pois o interesse local se reflete sobre os interesses regionais ou nacionais, visto que o benefício acarretado a uma parte do todo melhora o próprio todo. Os interesses locais são os que dizem respeito às necessidades imediatas do Município, tendo influência sobre as necessidades gerais. (FERREIRA, 2002, p. 271)

Esclareça-se que o interesse local, em verdade, não corresponde ao interesse exclusivo do Município, nem mesmo interesse privativo da localidade ou dos munícipes, mas o que define e caracteriza esse conceito é a predominância do interesse do Município sobre o interesse da União ou do Estado. (BASTOS, 2001, p. 321)

Não por outra razão é que, também, a Constituição Federal, em seu artigo 182, estabelece que a política de desenvolvimento urbano, executada pelo Poder Público municipal, conforme diretrizes gerais fixadas em lei, tem por objetivo ordenar o pleno desenvolvimento das funções sociais da cidade e garantir o bem-estar de seus habitantes.

$\mathrm{O}$ art. 182 da Constituição Federal, além de delegar a execução da política de desenvolvimento urbano aos entes municipais, mencionou a primeira vez na história do país as "funções sociais da cidade" como o objetivo da política urbana. O princípio da função social da propriedade tem previsão constitucional desde a Carta Magna de 1934 todavia, ao incluir a expressão "funções sociais da cidade", o constituinte de 1988 além de ter demandado um esforço doutrinário de definição do sentido e do alcance dessa expressão, obviamente deu um salto de escala do bem individual "lote" (cuja propriedade também deverá atender a sua função social) para 
o bem coletivo "cidade", que, como totalidade, também deverá ser capaz de atender as suas funções sociais. A constituição de 1988, portanto, rompe com uma visão de "urbanismo lote a lote", de responsabilidade do proprietário, para pensar a cidade como um todo, demonstrando a intenção de fazer com que o país passasse a tratar o urbanismo como uma função pública e a própria cidade a ser tratada como um bem coletivo. (ALFONSIN, 2012. p. 323).

Na Constituição Federal de 1988 a cidade possui um papel de extrema relevância, atribuindo-se a ela a roupagem de ambiente de acesso a direitos e geração de renda, devendo, por essa razão, haver a devida correspondência por parte dela e a satisfação das expectativas geradas aos indivíduos.

O direito à cidade é constituído pelas funções da cidade, principalmente pela função social que lhe é atribuída, correspondente à realização do conceito de espaço público como elemento mediador na desejada relação de equilíbrio entre o meio ambiente natural e o construído. Portanto, a cidade corresponde ao local propício para a efetivação da cidadania, do respeito à dignidade humana e demais direitos. (LEFEVBRE, 2005, p. 56)

Como forma de regulamentar os artigos 182 e 183 da Constituição Federal, foi criado o Estatuto da Cidade (Lei $\mathrm{n}^{\circ} 10.257 / 2001$ ), estabelecendo normas de ordem pública e interesse social que regulam o uso da propriedade em prol do bem coletivo, da segurança e do bem-estar dos cidadãos, bem como do equilíbrio ambiental, evidenciando a cidade como ambiente de acesso a direitos individuais e coletivos, servindo ela como instrumento à satisfação da coletividade dentro do contexto do Estado.

Nesse aspecto, cumpre ressaltar que a Constituição Federal estabelece, em seu artigo $5^{\circ}$, um rol de direitos e garantias individuais de liberdade, tratando-se muito mais de um direito de defesa do indivíduo contra as ações do Estado que necessariamente políticas a serem implementadas pelo Poder Público para a satisfação dos interesses dos integrantes da sociedade.

Por outro lado, o artigo $6^{\circ}$ da Constituição Federal estabelece um rol exemplificativo de direitos sociais, prestacionais pelo Poder Público, elencando-os em seu texto como educação, saúde, alimentação, trabalho, moradia, lazer, segurança, previdência social, proteção à maternidade e à infância, além da assistência aos desamparados.

Esses direitos sociais, enunciados em norma constitucional, são entendidos como uma dimensão dos direitos fundamentais do homem, correspondendo a prestações positivas, 
ações afirmativas a serem proporcionadas pelo Estado, de forma direta ou indireta, objetivando proporcionar melhores condições de vida aos mais necessitados, aqueles mais fracos no contexto social, reduzindo, por consequência, situações sociais desiguais. (SILVA, 2011, p. 196)

O escopo dos direitos sociais é que sirvam de pressupostos de gozo dos direitos individuais, criando mecanismos de maior efetividade para propiciar a igualdade material, aquela que acontece na realidade e se diferencia da igualdade formal, que corresponde ao tratamento igualitário a todos em face das previsões legais no ordenamento jurídico. Por sua vez, a igualdade real ou material proporciona condições mais compatíveis para o efetivo exercício das liberdades dos indivíduos (SILVA, 2011, p. 197)

Para que os direitos sociais sejam disponibilizados aos indivíduos, imperiosa se faz a prestação estatal nesse sentido, materializada pela adoção de políticas públicas. Ou seja, as políticas públicas implementadas pelo Estado encontram sua razão principal de existência nos direitos sociais, tendo em vista que a maioria desses direitos apenas são concretizados mediante a atuação do Estado por prestações positivas.

Cumpre esclarecer que os direitos sociais, que conforme mencionado são objeto de políticas públicas, não correspondem a direitos de igualdade. Pelo contrário, são eles a representação da desigualdade, da ocorrência de preferências, para que com medidas até mesmo discriminatórias seja possível compensar as injustiças que comumente são perpetradas pela desigualdade. Esse tratamento diferenciado em relação aos indivíduos ocorre para tentar disponibilizar a todos o acesso às oportunidades. (SARLET, 2006, p. 302)

Pelo disposto no artigo $5^{\circ}, \S 1^{\circ}$, da Constituição Federal, as normas definidoras dos direitos e garantias fundamentais possuem aplicação imediata, ou seja, irradiam seus efeitos desde a inserção no ordenamento jurídico. Entretanto, a eficácia dessas normas, quando se trata de direitos sociais, é limitada, carecendo de concretização em decorrência da dependência em relação às políticas públicas a serem implementadas pelo Estado.

Tratando-se de prestações positivas pelo Estado, em regra os direitos sociais demandam que recursos financeiros sejam despendidos para a sua promoção. Nesse ponto reside o maior problema enfrentado pelo Poder Público, tendo em vista que, infelizmente, a história tem demonstrado a impossibilidade de atendimento a todas as demandas sociais.

Ocorre que, em decorrência da escassez de recursos e a instabilidade econômica existente, provocada pelos desequilíbrios de mercado, há inegavelmente uma repercussão de 
efeitos em relação à luta por reconhecimento de direitos, dificultando consideravelmente que o acesso a direitos e a geração de renda tenham condições de caminhar juntos.

Tem-se conhecimento de que os recursos financeiros são aquém do necessário para a satisfação integral dos anseios dos indivíduos. Porém, a adoção de medidas de cunho material e jurídico deve ocorrer objetivando a redução das desigualdades, dependendo, para tanto, de certa disponibilidade de recursos por parte do Estado. (MORAES, 2016, p. 314)

Sem adentrar ao mérito acerca da essencialidade dos direitos sociais para a sociedade, além da sua importância e caráter cogente enquanto norma constitucional, cumpre verificar pela análise econômica do direito, implicando em perseguir o emprego dos recursos do Estado de forma eficiente, a melhor forma de atingir o maior número de pessoas com o mesmo recurso. (TIMM, 2010, p. 52)

Nesse sentido, apesar da competência para a distribuição de riquezas ser essencialmente atribuída, no contexto da democracia, ao sistema político, detentor dos mecanismos de implementação de políticas públicas, convém realizar um planejamento do gasto público no orçamento do Estado, elegendo as prioridades, a fim de, efetivamente, alcançar o maior número possível de beneficiários.

A partir da análise da Constituição Federal é inegável a determinação ao Estado que sejam implementados os direitos sociais associados a um grau de assistencialismo social, especialmente considerando a preocupação do constituinte originário com a vinculação e cumprimento das obrigações do modelo de Estado voltado à Justiça Social. (TIMM, 2010, p. 54)

Portanto, o Estado é o principal promotor do desenvolvimento, através do seu planejamento e gestão financeira, na realização das escolhas alocativas. Nesse sentido, as decisões de planejamento e execução orçamentária possibilitam ao Estado atuar de forma mais ampla para modificar as estruturas socioeconômicas, além de redistribuir renda e reduzir as desigualdades sociais e regionais, realizando a integração social e política da população. (BERCOVICI, 2006, p. 158)

Ao analisar a implementação de políticas públicas, voltadas à inclusão e assistência social, faz-se necessário verificar os mecanismos de implementação das medidas no espaço local, bem como a adaptação dos atores sociais ao contexto definido pelo Poder Público. Por esse razão o espaço local ganha maior relevância para o fortalecimento da qualidade de vida e das instituições, visto que em decorrência da proximidade das demandas sociais, consegue 
com maior efetividade atender às normas constitucionais de proteção social a quem está em situação de vulnerabilidade.

Resta enaltecido, nesse aspecto, o princípio da subsidiariedade para a implementação de políticas públicas, considerando que a Administração Pública local é a detentora de maior conhecimento empírico acerca das necessidades da coletividade, conseguindo se aproximar da população por meio de escolhas alocativas tendentes à obtenção do maior êxito possível.

As políticas públicas desenvolvidas no contexto local tomam nova conscientização em relação ao conceito político de federalismo. Isso, pois, a atuação no âmbito local tende a fortalecer a estrutura federativa e resulta na valorização da autonomia local e regional, favorecendo a diminuição das desigualdades no âmbito da cidade, visto que políticas públicas demasiadamente centralizadoras não conseguem atingir a todos os cidadãos. (BARACHO, 1996, p. 20)

A atuação do Poder Público local, acompanhada da participação ativa da população na discussão em relação a temas que caracterizam necessidades concretas faz com que o federalismo se consolide de forma ainda mais ampla, afastando a ideia de que o Estado seria um "corpo estranho", alheio às necessidades concretas da população, bem como afastando a perspectiva de cidadania sob a ótica puramente burocrática (BARACHO, 1996, p. 21)

A atribuição de poder, pela Constituição Federal, à cidade consolida a ideia de que esse é o ambiente de acesso a direitos pelos indivíduos, principalmente para a participação democrática nas escolhas e, por conseguinte, nos rumos a serem tomados pelo Estado em relação ao tratamento despendido à coletividade.

A cidade recebe, portanto, o status de essencialidade na concretização da participação democrática dos indivíduos nas decisões da sociedade e também no reconhecimento e na promoção dos direitos sociais, enquanto direitos prestacionais. Porém, a relevância da cidade não se limita às escolhas alocativas como forma de políticas públicas, mas vai além na salvaguarda de direitos dos indivíduos.

Compete à cidade, também, garantir direitos de defesa, não incidindo sobre ela apenas a eficácia vertical dos direitos fundamentais, mas também a eficácia horizontal dos direitos fundamentais, de modo a garantir que nas relações entabuladas diretamente entre os particulares, não mais entre o Estado e os particulares, seja assegurada a igualdade jurídica, de forma coordenada, a partir das normas constitucionais. 
A liberdade dos indivíduos, então, está atrelada à concretização dos direitos fundamentais, à igualdade material, não meramente formal. Com isso, a cidade assume papel de extrema relevância, pois suas políticas públicas não correspondem exclusivamente ao assistencialismo como fornecimento direto dos direitos aos indivíduos, mas também por meio da implementação de mecanismos de crescimento e desenvolvimento econômico para o aumento das riquezas e, assim, a geração de renda à coletividade.

Assim, os indivíduos encontram a razão de permanecer no contexto da cidade, vivendo de forma satisfatória e usufruindo de sua liberdade, quando o direito à cidade é concretizado, sendo ela um local de encontro de todos, tendo a cidade um valor de uso, não mais de troca.

Os indivíduos, no ambiente da cidade, precisam ser integrados, de fato fazer parte, pertencer à cidade, colaborando para o seu constante desenvolvimento e melhora das condições à coletividade, mas ao mesmo tempo, de forma recíproca, recebendo a atenção por parte do Poder Público no sentido de assegurar os direitos individuais necessários à sua satisfação enquanto pessoa.

\section{CONSIDERAÇÕES FINAIS}

Dentro do modelo federativo de organização do Estado, adotado no Brasil, aos municípios resta, por normas constitucionais, assegurada autonomia para desenvolver as atividades que lhe forem pertinentes à satisfação dos interesses coletivos. Por ser o ente federativo mais próximos às demandas sociais e que melhor pode diagnosticar as situações, é na cidade que se estabelece a maior gama de necessidades e políticas públicas voltadas ao reconhecimento de direitos e liberdade dos indivíduos.

Atribui-se, então, à cidade o encargo de diagnosticar o contexto social, a fim de constatar quais são as demandas existentes na localidade que ainda não foram devidamente atendidas e que, por consequência, estão proporcionando prejuízo aos integrantes desse espaço.

A ineficiência no atendimento às demandas sociais corresponde à inocorrência da promoção dos direitos fundamentais, constitucionalmente assegurados, fazendo com que os indivíduos não sejam detentores de liberdades, pois a falta de qualidade de vida lhes impossibilita realizar tudo que desejam, tornando-os submissos. 
No contexto da cidade, resta inegável a inexistência de recursos suficientes à disposição do Poder Público para a garantia dos direitos prestacionais. A realização de políticas públicas demanda investimento, que o Estado, por si só, não sendo ele diretamente o gerador de riquezas, não possui de forma ilimitada.

A necessidade da realização de escolhas alocativas limita consideravelmente o campo de atuação do Poder Público, que a partir de uma análise econômica precisa atuar no sentido de beneficiar a maior quantidade possível de pessoas com os escassos recursos de que dispõe.

Sendo assim, o Direito à Cidade vai além de aportes financeiros por parte do Estado para a satisfação das necessidades individuais daqueles integrantes desse espaço geográfico. Engloba a necessidade de, pelas escolhas alocativas, o Poder Público integre os indivíduos, fazendo-os participar da vida em sociedade, solidarizando-se com as demandas de toda a coletividade.

A partir do momento em eu os indivíduos se sentem integrantes desse territórios, atores sociais de fato, passam a se preocupar e a atuar com vias a concretizar as ações necessárias à satisfação coletiva. Por consequência, a satisfação coletiva gera o desenvolvimento, não apenas econômico, mas principalmente social, com a efetivação das liberdades individuais, pois só é verdadeiramente livre aquele que pode usufruir de seus direitos.

\section{REFERÊNCIAS}

ALFONSIN, Bethânia. Direito à cidade sustentável na nova ordem jurídico-urbanística brasileira: emergência, internacionalização e efetividade em uma perspectiva multicultural. In: Antonio Carlos Wolkmer; José Rubens Morato Leite. (orgs.). Os novos direitos no Brasil: natureza e perspectivas, uma visão básica das novas conflituosidades jurídicas. 1. ed. São Paulo: Saraiva, 2012.

BARACHO, José Alfredo de Oliveira. O princípio de subsidiariedade: conceito e evolução. Rio de Janeiro: 1996.

BASTOS, Celso Ribeiro. Curso de direito constitucional. 22. ed. São Paulo: Saraiva, 2001.

BERCOVICI, Gilberto. As origens do Direito Econômico: homenagem a Washington Peluso Albino de Souza. Revista da Faculdade de Direito da UFMG, Número especial em homenagem a Washington Peluso Albino de Souza. 2013. 
BERCOVICI, Gilberto. Planejamento e políticas públicas: por uma nova compreensão do papel do Estado. In: DALLARI, Maria Paula (org.). Políticas públicas: reflexões sobre o conceito jurídico. São Paulo: Saraiva, 2006.

BONAVIDES, Paulo. Do estado liberal ao estado social. 7. ed., São Paulo: Malheiros, 2004.

DERANI, Cristiane. Direito Ambiental Econômico. 2. ed. ver. São Paulo: Max Limonard, 2001.

FERREIRA, Fátima de Paula; CASTRO, Larissa de Paula Gonzaga. O direito ao desenvolvimento como direito de Igualdade de oportunidades entre as nações. In: Revista Anhangüera, v.5 n.1 jan./dez. 2004. p.31-44.

FERREIRA, Luiz Pinto. Curso de direito constitucional. 18. ed. São Paulo: Saraiva, 2002.

FEITOSA, Maria Luiza Alencar Mayer. Direitos humanos de solidariedade: avanços e impasses. Curitiba: Appris, 2013.

HARVEY, David. Rebel Cities: From the Right to the City to the Urban Revolution, New York: Verso, 2012.

LEFEVBRE, Henri. O direito à cidade. 5 ed. São Paulo: Centauro, 2005.

MACHADO SEGUNDO, Hugo de Brito. Amartya Sem como intérprete e crítico da teoria da justiça de John Rawls. Revista PGM - Procuradoria do Município de Fortaleza, [S.I], v. 17, p. 427-440, dez. 2009.

MORAES, Alexandre de. Direito Constitucional. 32. ed. São Paulo: Atlas, 2016.

PIOVESAN, Flávia. Direitos sociais, econômicos e culturais e direitos civis e políticos. SUR - Revista Internacional dos Direitos Humanos. Ano I, Número I, 2004.

SARLET, Ingo Wolfgang. A eficácia dos direitos fundamentais. 6 ed. Porto Alegre: Livraria do Advogado, 2006.

SEN, Amartya. Prefácio. In: BARRAL, Welber (org). Direito e Desenvolvimento: Análise da ordem jurídica brasileira sob a ótica do desenvolvimento. São Paulo: Editora Singular, 2005 .

A ideia de justiça. São Paulo: Companhia das letras, 2011.

Desenvolvimento como liberdade. São Paulo: Companhia das letras, 2010.

SILVA, José Afonso da. Curso de Direito Constitucional Positivo. 33. ed. São Paulo: Malheiros, 2011.

TIMM, Luciano Benetti. Qual a maneira mais eficiente de prover direitos fundamentais: uma perspectiva de direito e economia. 2. ed. ver. e ampl. Porto Alegre: Livraria do Advogado, 2010. 
VEIGA, José Eli da. Desenvolvimento sustentável: desafio do século XXI. Rio de Janeiro: Garamond, 2010. 